\title{
UTILIZAÇÃO DE CARVÃO VEGETAL NAS VENTANEIRAS DOS ALTOS-FORNOS DA USIMINAS*
}

\author{
Wemerson Junio Gandra ${ }^{1}$ \\ Marcello Barros Sabadini2 \\ Rafael Eduardo Gomes Ribeiro ${ }^{3}$ \\ Gustavo Serrano dos Santos ${ }^{4}$
}

\section{Resumo}

Para a redução do minério de ferro no alto-forno é necessária a utilização de uma fonte de carbono, que pode ser encontrada no carvão mineral e/ou carvão vegetal. Diante do cenário atual, a busca constante por maior competitividade, associada ao atendimento da qualidade e aos requisitos ambientais, exige a implementação de várias ações alternativas no processo de fabricação de gusa. Dentre elas, destacase a utilização de combustíveis alternativos no sistema de injeção dos altos-fornos, como por exemplo, a substituição parcial do carvão mineral pelo carvão vegetal. Do ponto de vista ambiental, é altamente favorável a utilização de uma fonte renovável de carbono. O objetivo desse trabalho é apresentar a adequação do processo, desde o recebimento do material até sua injeção nos altos-fornos, bem como os resultados já alcançados e os desafios futuros. A utilização do carvão vegetal na mistura de carvão pulverizado resulta em flexibilidade na utilização de matérias primas e contribui para preservação do meio ambiente.

Palavras-chave: Alto-Forno; PCl; Carvão Vegetal.

\section{USE OF CHARCOAL IN USIMINAS BLAST FURNACE'S TUYERES}

\begin{abstract}
For the iron ore reduction in a blast furnace it is necessary to use a carbon source, which can be found in mineral coal or charcoal. Given the current scenario of greater competitiveness of the steel market, associated with quality and environmental requirements, several alternatives action's implementation are necessary in the iron making process. Among them, the partial substitution of mineral coal by charcoal for injection in the blast furnace system stands out. From the environmental point of view, the use of a renewable carbon source is highly favorable. The objective of this paperwork is to present the process adequation, since the material receiving until the injection system, as well as the results already achieved and future challenges. The utilization of charcoal in pulverized mixture results in flexible raw material choices and contributes to environment protection.
\end{abstract}

Keywords: Blast Furnace; PCI; Charcoal.

Técnico de Produção, Gerência Técnica de Redução; Usiminas, Ipatinga, MG, Brasil. Engenheiro Metalurgista, Gerência Técnica de Redução; Usiminas, Ipatinga, MG, Brasil. Engenheiro Metalurgista, Gerência Técnica de Redução; Usiminas, Ipatinga, MG, Brasil.

Engenheiro Metalurgista, Gerência de Coquerias e Pátio de Carvão; Usiminas, Ipatinga, MG, Brasil. 


\section{INTRODUÇÃO}

Para aumentar a produtividade do alto-forno e reduzir ao mesmo tempo o consumo de combustível por tonelada de ferro-gusa líquido produzido (coke rate), são empregadas técnicas de injeção pelas ventaneiras de materiais que podem atuar como combustíveis, bem como o enriquecimento do ar de combustão com 0 oxigênio. Teoricamente, qualquer material que contenha alto teor de hidrocarbonetos pode ser injetado pelas ventaneiras do alto-forno. A lista de materiais já testados é grande e inclui: plásticos picotados, óleo combustível, álcool, alcatrão, gás natural, borras oleosas, coque de petróleo, pneus, carvão vegetal e carvão mineral pulverizado, entre outros. Uma das razões para a admirável versatilidade do altoforno em consumir vários tipos de materiais através da injeção pelas ventaneiras é o fato de que, na zona de combustão, as temperaturas de chama são tão altas que todos os materiais injetados são convertidos em moléculas simples como $\mathrm{H}_{2}$ e $\mathrm{CO}$, que atuarão como combustíveis no processo.

O carvão pulverizado, seja vegetal ou mineral, é atualmente o material mais usado no Brasil na injeção de combustíveis em alto-forno pelas ventaneiras. Também pode ser feita a mistura destes materiais, em função da disponibilidade e necessidade de reaproveitamento de coproduto. Ressalta-se que esta é atualmente uma prática consolidada, sendo aplicada em mais de 400 altos-fornos no mundo e em mais de 30 altos-fornos no Brasil. Entretanto, vários estudos continuam sendo realizados para melhoria constante dos processos, equipamentos e das matérias-primas injetadas, visando o aumento de sua eficiência, almejando atingir taxas de injeção superiores a $200 \mathrm{Kg} / \mathrm{t}$ de ferro-gusa. A escolha do material mais adequado passa pela análise dos aspectos operacionais, ambientais e econômicos desta injeção [1]. Atualmente, a Usina de Ipatinga importa aproximadamente 360 mil toneladas de carvão mineral por ano, que é utilizado na injeção direta nos altos-fornos para a fabricação do ferro gusa. Em função do elevado custo de aquisição deste combustível, associado à dependência de fontes estrangeiras, esforços são envidados visando minimizar esses problemas. Além disso, por se tratar de um combustível fóssil, o carvão mineral é o grande gerador de $\mathrm{CO}_{2}$ na siderurgia.

Diante do cenário atual de maior competitividade do mercado siderúrgico, ações voltadas para aumento de produtividade, associadas com a manutenção de qualidade e atendimento aos requisitos ambientais são debatidas constantemente. Uma alternativa a essas exigências foi a utilização de biomassa (moinha de carvão vegetal) em substituição parcial aos carvões minerais utilizados na injeção nos altosfornos.

O carvão vegetal é o produto sólido obtido por meio da carbonização da madeira, cujas características dependem das técnicas utilizadas para sua obtenção e o uso para o qual se destina.

A pirólise ou carbonização da madeira (lenha) é um processo desencadeado quando esta é aquecida, na ausência do ar, em temperaturas acima de $280^{\circ} \mathrm{C}$, provocando a extensa modificação dos seus componentes, até se transformarem em vapores de produtos voláteis, gases não condensáveis e o carvão vegetal.

A madeira é composta, basicamente, de carbono, oxigênio e hidrogênio. Estes três elementos se combinam de maneiras diferentes, formando compostos de estrutura relativamente complexa, que são: celulose, hemicelulose e lignina. Durante o aquecimento, estes compostos são degradados, deixando um resíduo rico em carbono, o carvão vegetal. O composto que mais contribui para a formação do 
carvão vegetal é a lignina, pois, os outros praticamente se degradam totalmente na temperatura de carbonização, ao contrário da lignina.

A carbonização da madeira se processa em três etapas:

- Secagem - Antes que a madeira possa ser carbonizada, a sua umidade deve ser eliminada. A secagem é o principal período endotérmico da carbonização.

- Pirólise - Nessa etapa a estrutura química da madeira é destruída sob temperatura elevada na ausência do ar. Depois de iniciada, a etapa da pirólise é exotérmica e a temperatura se eleva até $350-380^{\circ} \mathrm{C}$, com a emissão de hidrocarbonetos gasosos e a geração de produto sólido (carvão vegetal). As espécies gasosas são: $\mathrm{CO}, \mathrm{CO}_{2}, \mathrm{H}_{2}, \mathrm{CH}_{4}$, vapor d'água, hidrocarbonetos gasosos, vapores de alcatrão, de metanol, de ácido acético e do licor pirolenhoso. Quando liberados para a atmosfera, a condensação desses vapores produz líquidos nocivos ao meio ambiente.

- Resfriamento - O carvão vegetal produzido deve ser resfriado, devendo o forno ou retorta permanecer completamente selado para evitar a queima do carvão vegetal pelo ar atmosférico eventualmente infiltrado [1] ${ }^{(1)_{-}}$

Segundo a Sociedade Brasileira de Silvicultura, o Brasil é um dos maiores produtores de carvão vegetal, respondendo por cerca de 1/3 da produção mundial. O setor industrial caracteriza-se como o principal consumidor de carvão vegetal, sendo responsável pelo consumo de $89 \%$, das 10,5 milhões de toneladas carvão vegetal produzidos no ano de 2007 [2]. Dentro desse valor, cerca de $84 \%$ são destinados a produção de ferro-gusa e aço nas siderúrgicas [3].

Neste contexto, decidiu-se pela aquisição de carvão vegetal para injeção nas ventaneiras dos altos-fornos da Usiminas.

O presente trabalho tem por objetivo apresentar as adaptações realizadas no processo para possibilitar o recebimento e a dosagem de carvão vegetal substituindo parcialmente o carvão mineral, os resultados alcançados e os desafios futuros.

\section{MATERIAIS E MÉTODOS}

\subsection{Características do Carvão Vegetal x Mineral}

Tanto o carvão vegetal, quanto o carvão mineral são materiais ricos em carbono e que podem ser utilizados como agente redutor nos altos-fornos, com a finalidade de substituir parcialmente o coque.

Suas características se assemelham em partes e distinguem-se em alguns parâmetros. A tabela 1 mostra uma análise comparativa entre ambos.

Tabela 1. Resultados de qualidade do carvão mineral e vegetal

\begin{tabular}{|l|c|c|}
\hline \multicolumn{3}{|c|}{ Qualidade do carvão mineral x vegetal } \\
\hline Parâmetro & Carvão mineral & Carvão vegetal \\
\hline Matéria volátil (\%) & 22,1 & 25,1 \\
\hline Cinza (\%) & 10,8 & 8,5 \\
\hline Enxofre (\%) & 0,47 & 0,10 \\
\hline Carbono fixo (\%) & 67,1 & 66,3 \\
\hline PCl (cal/g) & 7.243 & 6.519 \\
\hline
\end{tabular}




\begin{tabular}{|l|l|l|}
\hline Combustibilidade (\%) & 60 & 72 \\
\hline HGI & 89 & 88 \\
\hline
\end{tabular}

Pode-se observar que o carvão vegetal possui menor teor de cinza e enxofre em comparação ao carvão mineral.

Além disso, ele possui maior combustibilidade devido a maior presença de poros em sua estrutura (figura 1).

a)

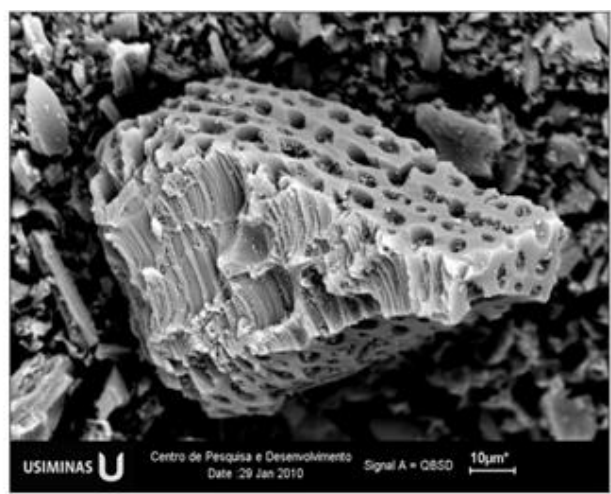

b)

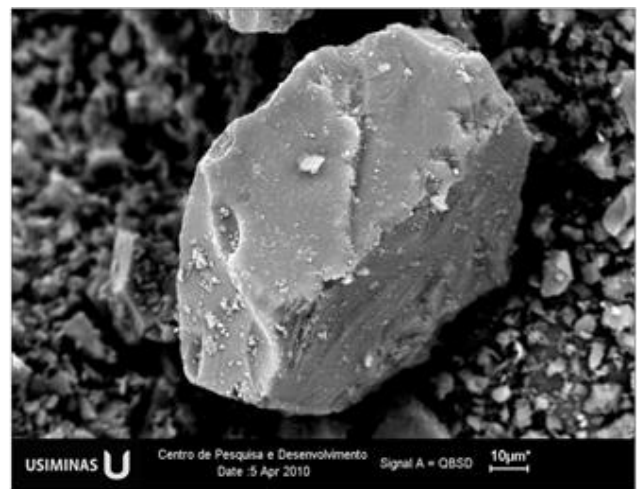

Figura 1. Fotomicrografia do carvão vegetal (a) e mineral (b).

Em contrapartida, seu poder calorífico é menor do que a do carvão mineral.

\section{2 - Adequação do sistema de recebimento e empilhamento}

Visando a utilização do carvão vegetal em substituição parcial do ao carvão mineral na mistura de Pulverized Coal Injection (PCI), foi adquirida aproximadamente, 600 toneladas para realização de testes industriais.

Devido à possibilidade de geração de emissão de particulado durante o recebimento do material, o carvão foi analisado em laboratório e encontrou-se umidade igual a 6\% Diante disto, vários testes foram realizados na área de estocagem do fornecedor, a fim de analisar qual umidade seria ideal para evitar possíveis emissões de particulados para a atmosfera durante o processo de recebimento na usina de Ipatinga.

Mediante os resultados dos experimentos, concluiu-se que a umidade ideal para o recebimento do carvão vegetal é de $20 \%$. Com este teor, a descarga deste material não causa problemas com emissão, como podemos ver na figura 2. 

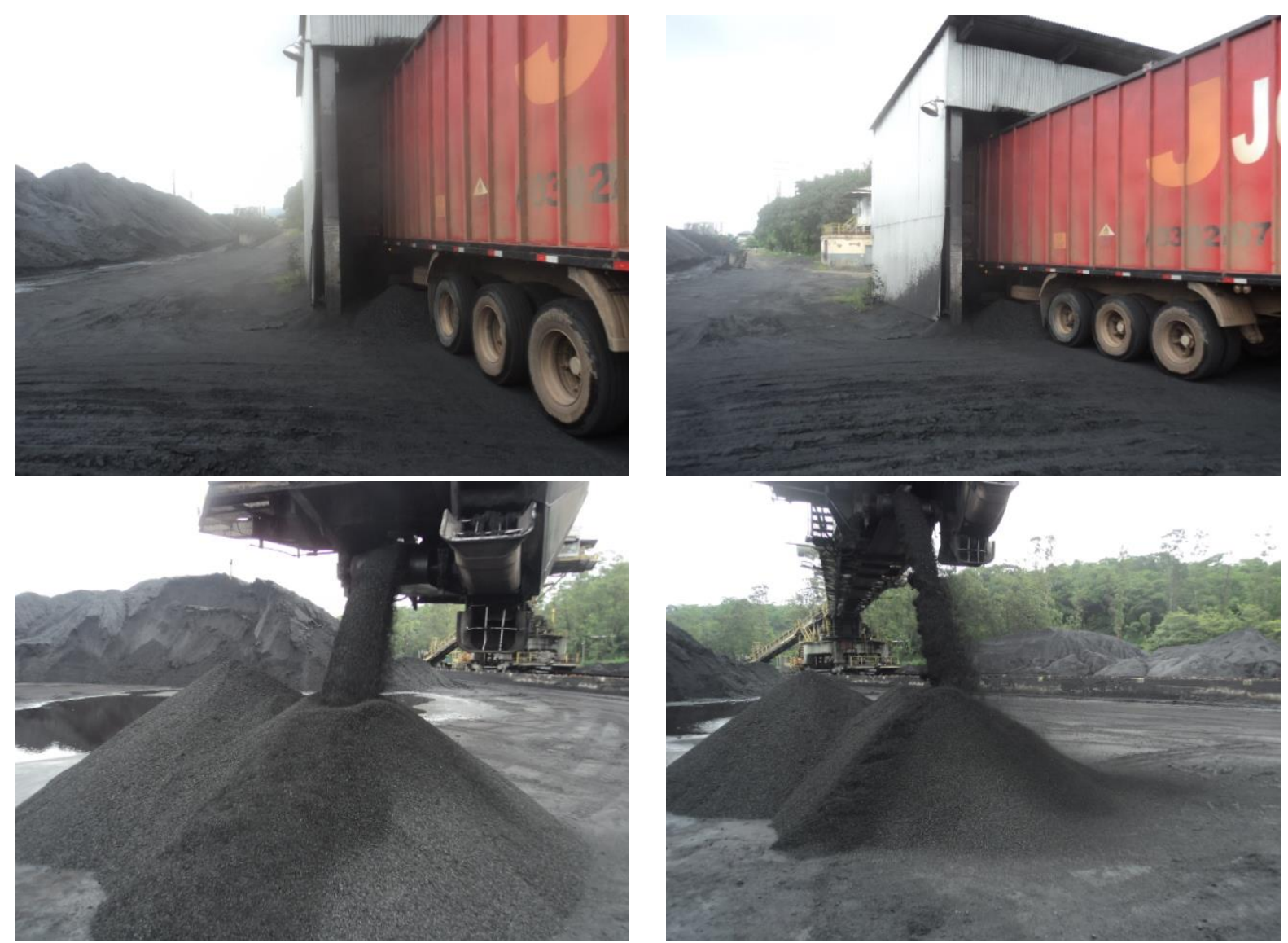

Figura 2. Recebimento e empilhamento do carvão vegetal com $20 \%$ de umidade.

\section{3 - Sistema de abastecimento}

O sistema de injeção de finos de carvão nos altos-fornos foi implantado na usina de Ipatinga em 1993. O sistema de injeção é composto de vários subsistemas, responsáveis pelas diversas etapas (abastecimento, moagem, secagem, transporte, armazenamento e injeção nos altos-fornos).

Em 2010, foi instalado no sistema de abastecimento de matérias primas um sistema para dosagem de rutilit (óxido de titânio) na mistura de carvão a ser injetada nos altos-fornos. Este material tem finalidade de auxiliar na formação da camada de proteção dos blocos de carbono do cadinho do alto-forno, quando o mesmo se encontra com temperaturas acima da especificação de trabalho. Este sistema é composto por um silo de $100 \mathrm{~m}^{3}$, uma balança dosadora com capacidade nominal de $35 \mathrm{t} / \mathrm{h}$ e um alimentador que direciona o fluxo para o silo ou para as plantas de secagem e moagem.

Devido à estabilidade da temperatura dos cadinhos dos altos-fornos da Usiminas, verificou-se a oportunidade de utilizar o sistema de dosagem de rutilit para dosar carvão vegetal na mistura de PCl. Assim, em novembro de 2016, iniciou-se o processo de dosagem de $10 \%$ de carvão vegetal na mistura de PCl.

Observa-se, na figura 4, que não houve injeção no período de 12 a 29 de dezembro de 2016 devido à necessidade de utilizar o sistema de dosagem para utilização de rutilit nos cadinhos dos altos-fornos. 


\section{Percentual de utilização de CV}

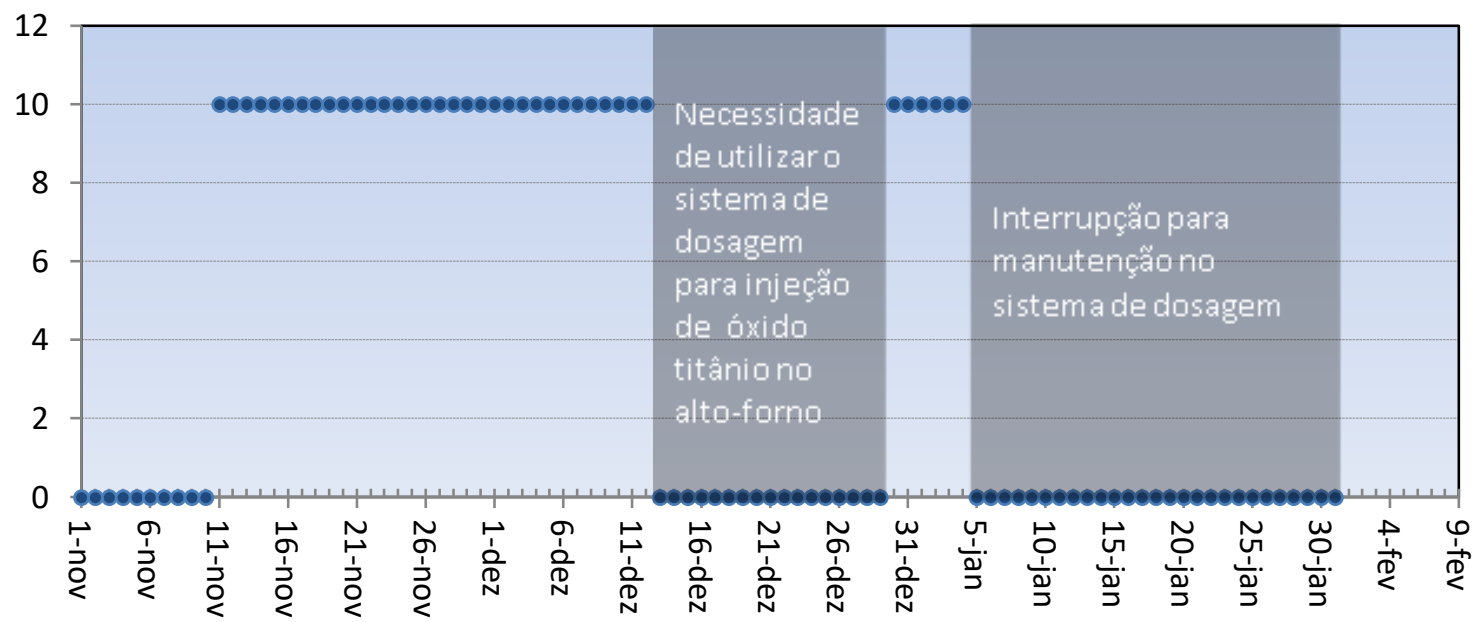

Figura 4. Percentual de utilização de carvão vegetal na mistura para PCl.

Visando melhorias, foi definida a necessidade de revisar todo o processo de abastecimento e dosagem de carvão vegetal. Para isto, foram envolvidas as equipes de diversas áreas para elaboração de plano de ações como instrumentação, automação, manutenção, gerência técnica.

A primeira ação foi implantar valores de set-point no silo de carvão vegetal, pois quando ele era abastecido, atingia-se o limite máximo de armazenagem e ainda remanescia de 14 a 24 toneladas de carvão vegetal nos transportadores de correia. Esse material era direcionado diretamente para os silos de granulados das plantas de PCl, causando obstrução por excesso de carvão vegetal na mistura.

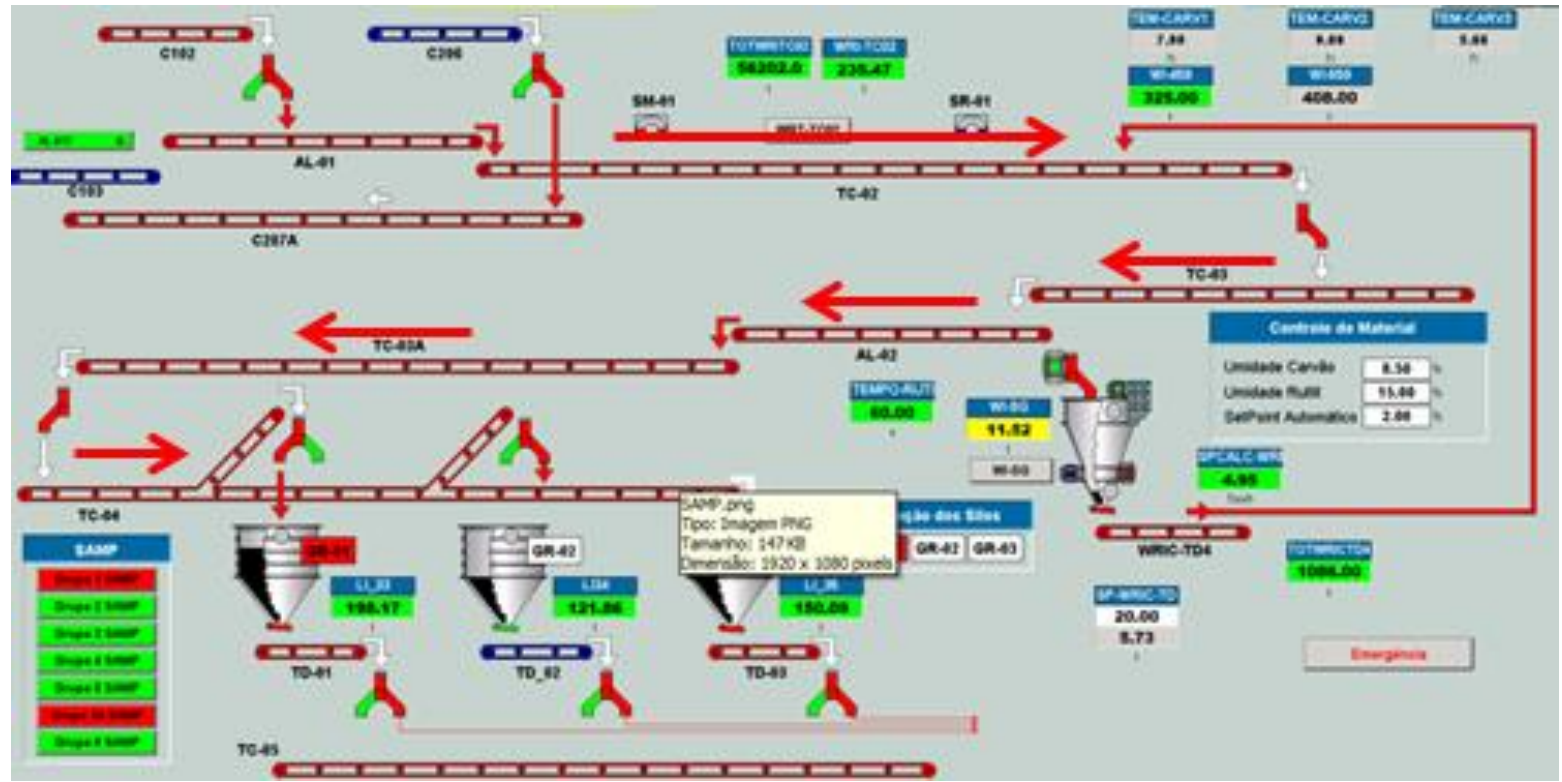

Figura 5. Fluxo de transporte do sistema de abastecimento de matéria prima das plantas de PCl.

Com a implantação dos limites analógicos, quando o silo de carvão vegetal atinge 5 toneladas, é exibido um alerta na tela do operador da sala de controle solicitando o abastecimento do silo. Após o início do abastecimento, no momento em que o silo 
atinge o valor de 6 toneladas, surge uma mensagem para o operador da sala de controle orientando-o a esvaziar a rota sem efetuar remoção e, neste mesmo instante, o sistema de rádio link emite um sinal para a recuperadora interrompendo a remoção do carvão.
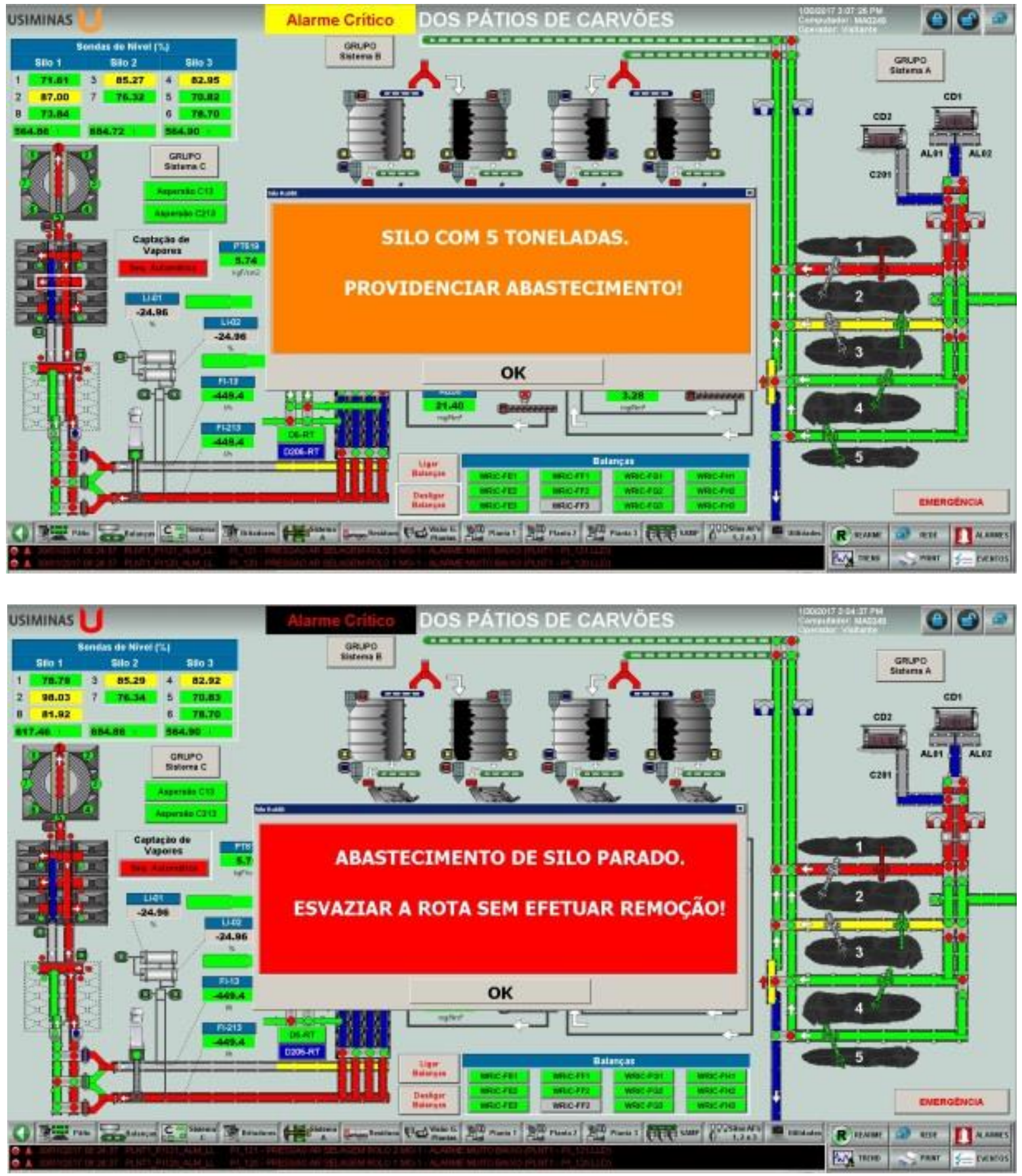

Figura 6. Mensagens de orientação operacional.

\section{4 - Sistema de dosagem}

A dosagem do carvão vegetal é realizada por uma balança dinâmica que retira o carvão vegetal do silo por gravidade e o dosa sobre o fluxo da correia que transporta o carvão mineral para os silos granulados das plantas de secagem e moagem. A 
correia possui uma balança que envia o sinal de pesagem do fluxo de carvão mineral para a balança, porém foram identificadas possibilidades no processo.

Este era um processo importante no sistema.

Para mitigar eventuais riscos, a balança foi programada para dosar o carvão vegetal em função do fluxo indicado da balança e dos resultados das análises de umidade dos carvões realizadas diariamente em laboratório. Através desta melhoria, foi possível dosar o carvão vegetal com confiabilidade no processo.

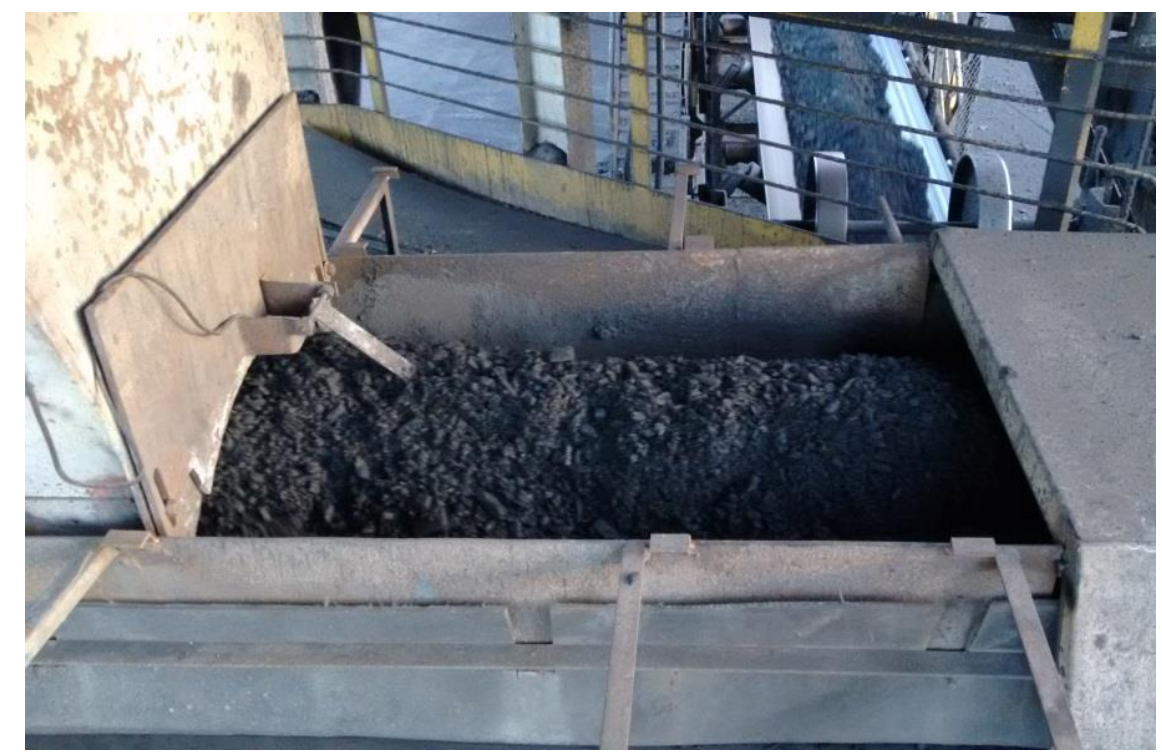

Figura 7. Balança dosadora com carvão vegetal.

Para acompanhamento e controle da dosagem foram implantados integradores das balanças e no supervisório de operação. Os integradores fazem a contabilização da quantidade de carvão que passou em cada balança e calcula, em porcentagem, a quantidade de carvão vegetal que foi dosada na mistura.

Além disso, os integradores registram a dosagem horária, diária e por turno de trabalho de cada equipe e registra em histórico para o sistema de automação.
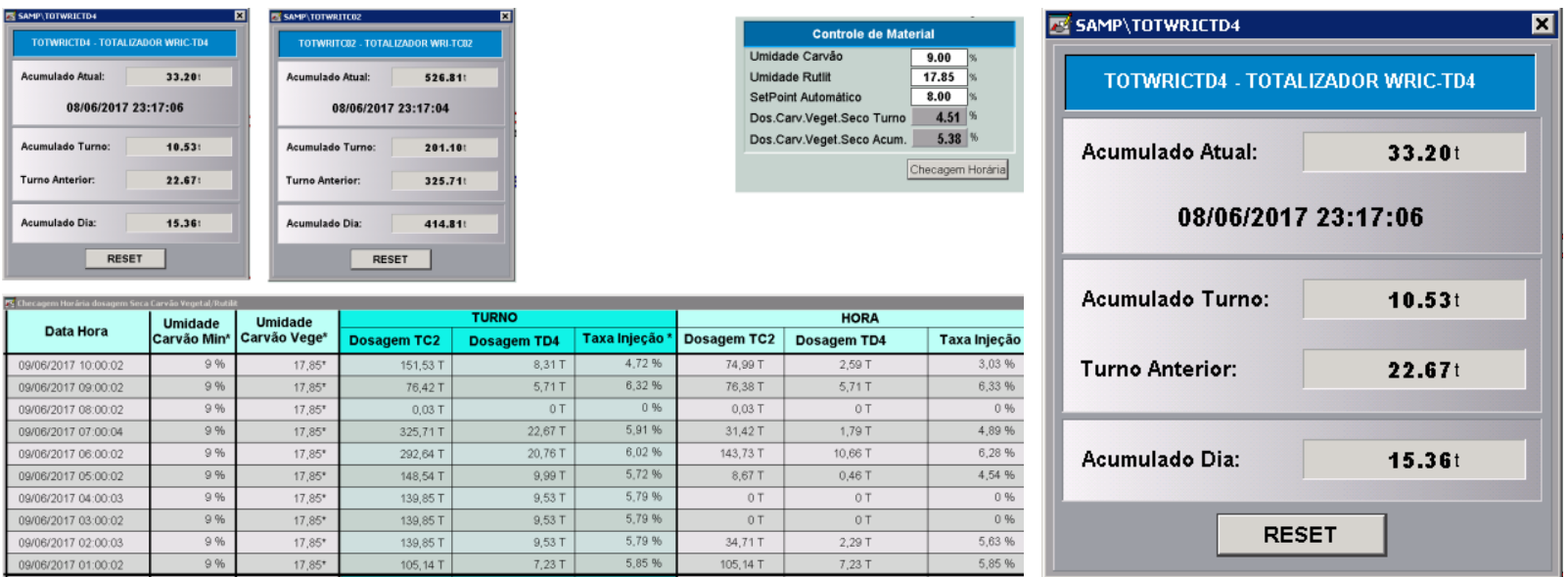

Figura 8. Integradores das balanças.

Todas as ações foram concluídas em fevereiro de 2017, ficando o sistema mais confiável para dosagem de carvão vegetal. 


\section{RESULTADOS E DISCUSSÃO}

\subsection{Dosagem do carvão vegetal}

No dia 16 de Em fevereiro de 2017, foi reiniciado a dosagem do carvão vegetal na mistura para $\mathrm{PCl}$. A princípio foi utilizado $2 \%$, de carvão vegetal na mistura aumentando gradativamente esse valor.

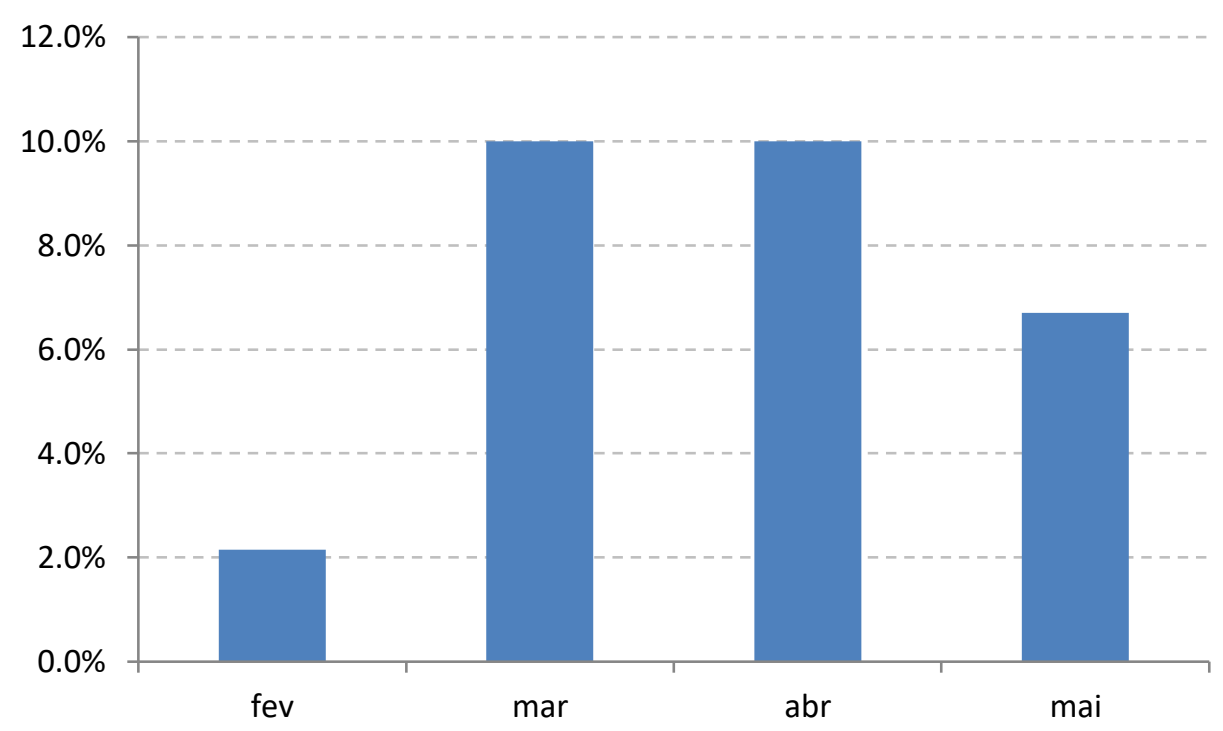

Figura 9. Participação do carvão vegetal no mix para PCI - 2017.

Nos meses de março e abril, o percentual alcançou 10\% (limite atual da balança dosadora). Em maio de 2017, esse percentual ficou abaixo do que estava sendo praticado $(6,7 \%)$, devido à necessidade de injeção de rutilit na mistura, visando controlar a temperatura do cadinho do alto-forno.

Ressalta-se que, após as melhorias implantadas, não houve interrupção operacional nas plantas de secagem e moagem em função de obstrução por carvão vegetal.

\subsection{Resultados nos altos-fornos}

Pode-se observar que não houve alteração nos parâmetros (sugestão citar coke rate-) operacionais de eficiência energética dos altos-fornos no período de injeção do carvão mineral associado com o vegetal. O coke rate e o fuel rate dos altos fornos permaneceram estáveis durante o período do teste como mostrado nas figuras 10 e 11. Destaca-se o período com injeção de 10\% de carvão vegetal (meses de março e abril de 2017). 


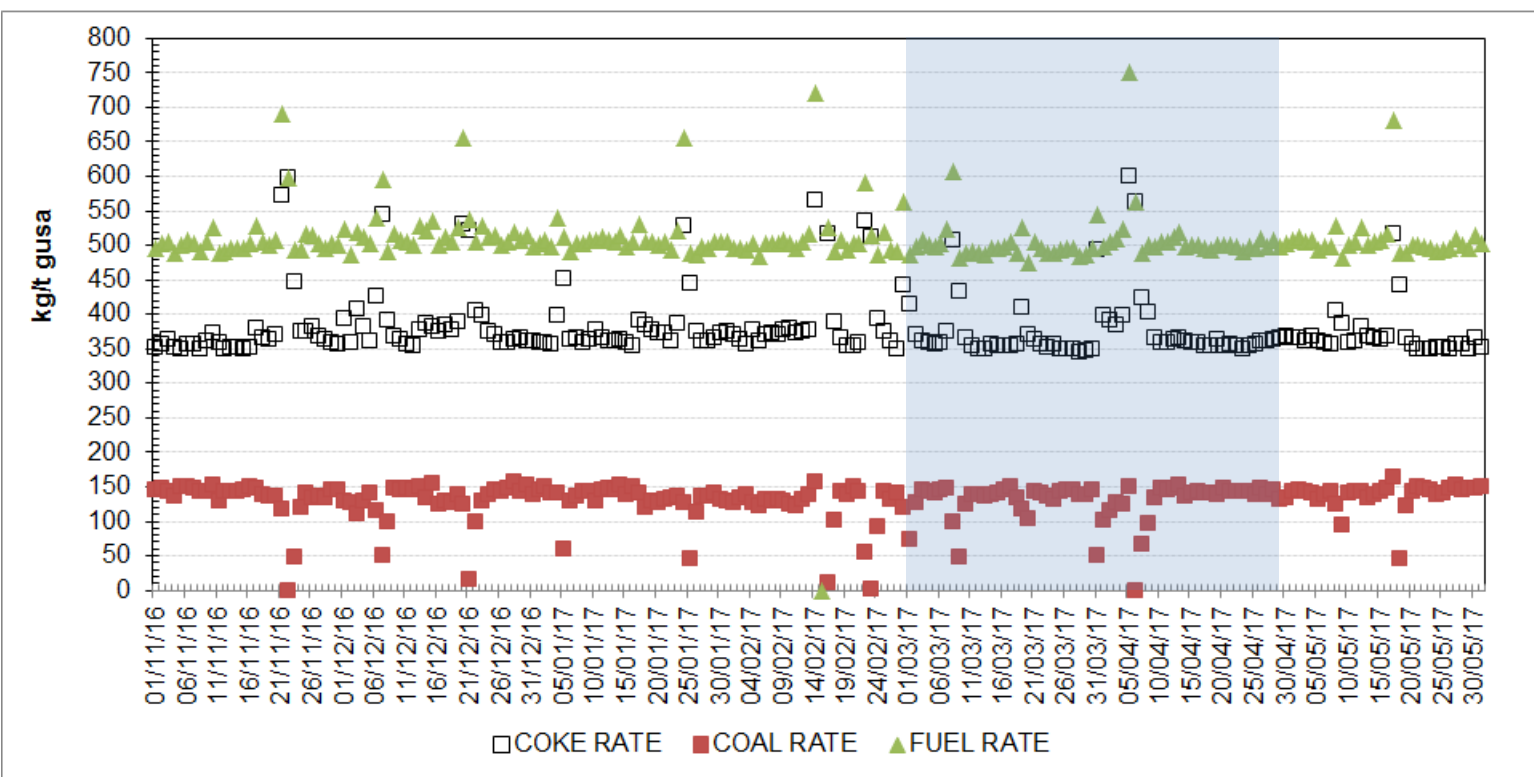

Figura 10. Parâmetros operacionais do Alto-Forno 2.

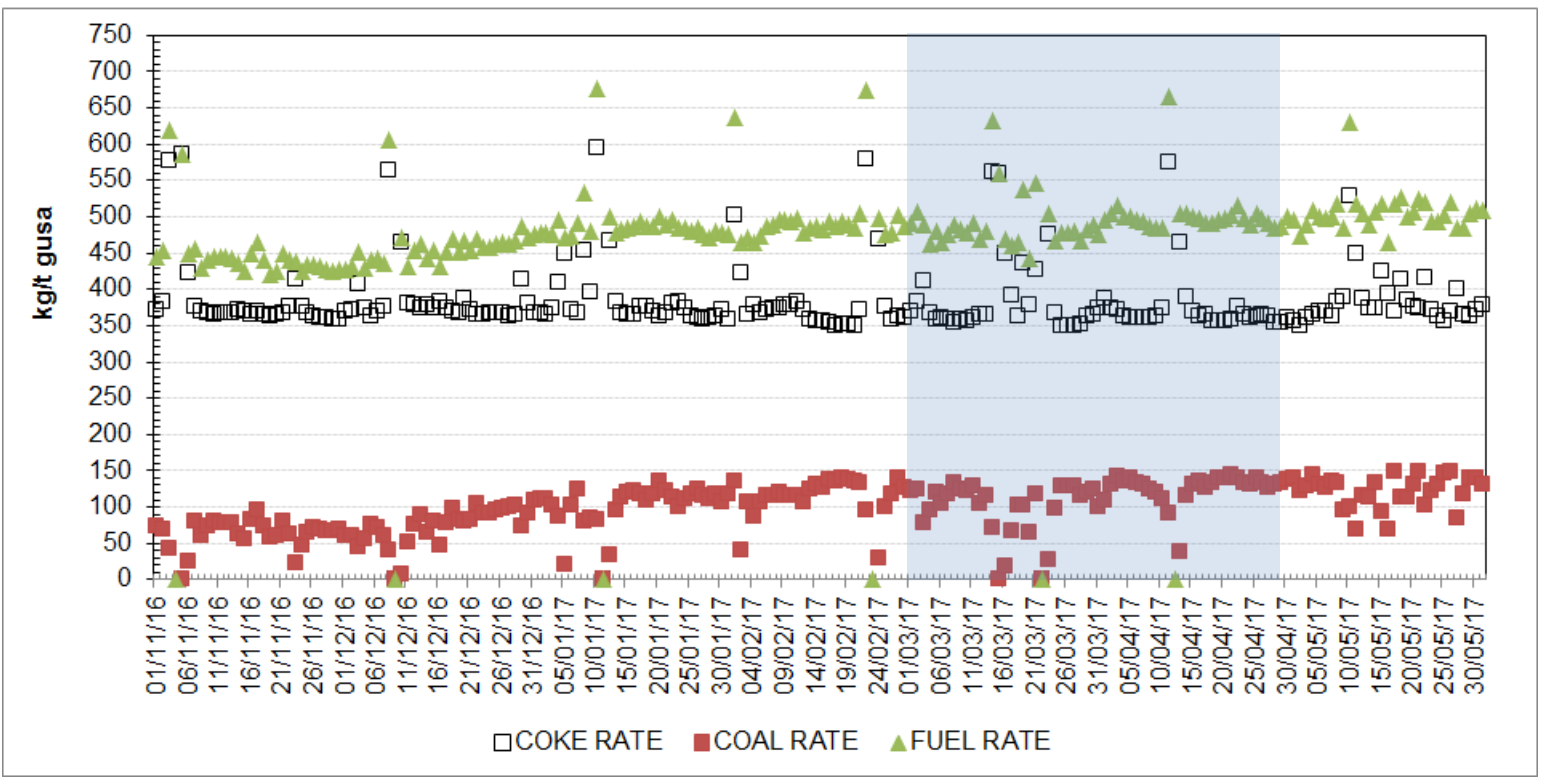

Figura 11. Parâmetros operacionais do Alto-Forno 3.

Vale ressaltar a injeção de gás natural nas ventaneiras do Alto-Forno 3 nos meses de novembro e dezembro de 2016 em função do alta do preço dos carvões adquiridos.

Objetiva-se, após ajustes eletromecânicos na balança dosadora e da maior disponibilidade de carvão vegetal, atingir $30 \%$ de carvão vegetal na mistura (benchmark).

\section{CONCLUSÃO}

A influência da injeção de carvão vegetal foi avaliada por meio de testes em escala industrial. 
É necessário realizar um controle minucioso em sua dosagem, a fim de prevenir falhas no processo de preparação e injeção do carvão pulverizado para melhor controle nos parâmetros de processo do alto-forno.

A utilização do carvão vegetal na mistura de $\mathrm{PCl}$ resulta em flexibilidade na utilização de matérias primas e contribui para preservação do meio ambiente.

\section{REFERÊNCIAS}

1 Rizzo, E. M. S.; Processo de Fabricação de Ferro-Gusa em Alto-Forno. ABM Associação Brasileira de Metalurgia, Materiais e Mineração. São Paulo, 2009.

2 Ben. Balanço Energético Nacional 2008 - Base 2007. Brasília, 2008.

3 MME - Ministério de Minas e Energia do Brasil. Balanço Energético Nacional, 2007. Disponível em:

https://ben.epe.gov.br/downloads/Resultados_Pre_BEN_2007.pdf Acesso em: 26 nov. 2008. 